\title{
Molecular characterization of the polyphenol oxidase gene in lulo (Solanum quitoense Lam.) var. Castilla
}

\section{Duverney Gaviria Arias ${ }^{1}$, Clara María Mejía Doria ${ }^{1,2 *}$, Lucero Rengifo Ramos ${ }^{1}$, Heydy Catalina Navia Morocho'}

\author{
${ }^{1}$ Centro de Biología Molecular y Biotecnología (CENBIOTEP), Facultad de Ciencias de la Salud, Universidad \\ Tecnológica de Pereira, Pereira, Colombia. \\ ${ }^{2}$ Ciencias Básicas y Tecnologías, Universidad del Quindío, Armenia, Colombia. \\ ${ }^{*}$ Corresponding autor: cenbiotep@utp.edu.co
}

Received: 3 October 2012; Accepted: 21 January 2013

\begin{abstract}
Lulo (Solanum quitoense Lam.) is an exotic fruit from the Andes Mountains with a high export potential. However, the browning that is produced during harvest and the postharvest processes alters the organoleptic and nutritional properties of this fruit, which has made its management as a fresh fruit difficult. The browning processes are regulated by the enzyme family of the polyphenol oxidases (PPOs) located in the thylakoids of the chloroplast. When there is damage at the tissue level, the phenolic compounds found in the vacuoles enter into contact with the polyphenol oxidase. This enzyme produces polymerization among the phenolic compounds, as well as between them and the proteins and cell walls. This study analyzed the polyphenol oxidase in lulo var. Castilla at the genetic level, based on DNA and RNA samples. The results showed a high level of homology with other polyphenol oxidases from plants. The highest degree of homology was found with Solanum melongena L., which belongs to the same clade, Leptostemonum. The tyrosinase and two copper-binding domains, characteristic of the polyphenol oxidase, the conserved residues that maintain the natural environment, the sequence of a signal peptide for targeting chloroplast, and the UTRA domain of transcription regulation for recognizing small molecules were identified. Southern blot was used to analyze the number of gene copies, identifying at least eight ones in the lulo genome.
\end{abstract}

Keywords: enzymatic browning, DNA sequencing, Solanaceae, UTRA domain.

\section{INTRODUCTION}

Lulo or naranjilla (Solanum quitoense Lam.) is a fruit that was originated in the highlands of the South American Andes in regions with temperate climates, low daylight, and altitudes ranging from 1,500 to $2,800 \mathrm{~m}$. Such species belongs to the Solanaceae family, which is of horticultural value in the tropical areas of the Americas, Africa, Asia, and Oceania (Medina et al., 2009). This fruit has a marked tendency to enzymatic browning, a process that causes changes in color and in taste, as well as losses in the nutritional value, which significantly limit the possibility of product marketing, whether for fresh consumption or for industrial processing (Shimizu et al., 2011). This phenomenon is caused by the activity of a family of enzymes known as polyphenol oxidases (PPOs) (EC 1.10.3.1, 1.10.3.2, and/or 1.14.18.1), which are localized within the plastids. The PPOs are metalloproteins that contain three different types of copper ions attached to histidines. They are responsible for the hydroxylation of monophenols to diphenols and the oxidation of the latter to $o$-quinones. Also, PPOs are synthesized in the cytoplasm in the form of preproteins $(60-70 \mathrm{kDa})$ and have a signal peptide in the amino terminus, which internalizes them in the chloroplast, where they are processed by stromal peptidases into functional proteins $(54-62 \mathrm{kDa})$ and then 
imported into the thylakoid lumen (Marusek et al., 2006). Many of them have a site for proteolytic processing near the carboxy-terminus (Marusek et al., 2006). The PPOs enter into contact with the phenolic compounds in the vacuoles only after some type of damage occurs in the plant (Shimizu et al., 2011).

The PPOs are enzymes with a broad distribution in higher plants. Their biological function is related to defense against herbivory and disease resistances, the different activities attributable to them include the biosynthesis of plant pigments and lignin polymers (Strack and Schliemann, 2001). They also participate in the oxidative polymerization of flavonoids (Schijlen et al., 2004) and induce an antinutritional function, so that after forming 0 -quinones, they can modify the proteins in the plants, reducing their nutritional value. Moreover, they can react with other molecules, producing brown or black pigmentation (Mayer, 2006). This type of action makes the PPO enzymes important in the food industry, given that during the processing of the fruits and vegetables, mechanical wounds are produced, forming o-quinones that modify the color, taste, texture, and nutritional properties, thereby affecting the quality of the products and causing up to $50 \%$ postharvest losses (Martinez and Whitaker, 1995).

The genes that encode the PPOs in higher plants range from four to eight, being organized in multigene families (Beecher and Skinner, 2011; Shetty et al., 2011; Shimizu et al., 2011). The several ones in vegetables are quite similar, both in their nucleotide sequence and immunological properties. In the case of the Solanaceae, extensive studies have been conducted on the organization of this gene family in tomatoes (Lycopersicon esculentum L. CV. VFNT Cherry) (Newman et al., 1993), in which there are seven nuclear genes located in a 165-kb locus in chromosome 8. They lack introns and are expressed through a mRNA of approximately $2 \mathrm{~kb}$ (Newman et al., 1993). In potatoes (Solanum tuberosum L.), five different types of cDNA have been isolated from PPOs, and each gene has a specific temporal and spatial pattern of expression (Thygesen et al., 1995). In eggplants, six of them were identified, which encode for two structural classes of PPOs (Shetty et al., 2011).

The evaluation and characterization of the PPO gene in lulo (Solanum quitoense Lam) var. Castilla are essential in the search for solutions to the enzymatic browning problems that happen in the cortex, and the pulp when the fruit is exposed to light, air and handling during its harvesting, storage, and processing. Its control would decrease postharvest losses, improve commercialization, and increase the agroindustrial exploitation of the fruit. This study presented the results obtained in the molecular analysis of the PPO in several plant tissues from the lulo plant.

\section{MATERIAL AND METHODS}

Plant material: Samples of young leaves, stems, fruits, and roots were taken from the lulo plants, and they were kept in liquid nitrogen and then stored at $-80^{\circ} \mathrm{C}$ until their processing time.

DNA extraction: $0.1 \mathrm{~g}$ of leaf tissue was macerated in liquid nitrogen, then $5 \mathrm{~mL}$ of extraction buffer, previously heated to $65^{\circ} \mathrm{C}$ [ $2 \%$ CTAB (hexadecyltrimethylammonium bromide), $100 \mathrm{mM}$ Tris $-\mathrm{HCl}(\mathrm{pH}=8.0), 20 \mathrm{mM}$ EDTA -ethylenediamine tetraacetic acid ( $\mathrm{pH}=8.0), 1.4 \mathrm{M} \mathrm{NaCl}$, $2 \%$ ß-mercaptoethanol], were added. The sample was incubated at $65^{\circ} \mathrm{C}$ for one hour, after which $5 \mathrm{~mL}$ of chloroform/isoamyl alcohol (24:1) was added. It was incubated again at $65^{\circ} \mathrm{C}$ during a 45 -minute period, and centrifuged at $3,000 \mathrm{rpm} / 4^{\circ} \mathrm{C}$ for ten minutes. The aqueous phase was recovered, and $-20^{\circ} \mathrm{C}$ isopropanol $(2 / 3$ of the recovered volume) was added. It was incubated at the same temperature for two hours, and centrifuged at $3,000 \mathrm{rpm} / 4^{\circ} \mathrm{C}$ for ten minutes. The precipitate was washed with a mixture of $1 \mathrm{~mL}$ ethanol at $76 \%$ and $10 \mathrm{mM}$ ammonium acetate and centrifuged at $3,000 \mathrm{rpm} / 4^{\circ} \mathrm{C}$ for ten minutes. Then, it was dried and resuspended in $200 \mu \mathrm{L}$ TE buffer $(10 \mathrm{mM}$ Tris- $\mathrm{HCl}$, $\mathrm{pH}=7.4 ; 0.1 \mathrm{mM}$ EDTA, $\mathrm{pH}=8$ ).

Extraction and purification of total RNA: The extraction and purification of the total RNA were done with $100 \mathrm{mg}$ of stems, fruits, and roots, each using the RNeasy ${ }^{\circledR}$ Plant Mini Kit (QIAGEN) following the manufacturer's recommendations.

Primer design: Given the absence of sequences reported for lulo, those corresponding to genes and mRNAs of the Solanaceae PPO enzyme reported in the National Center for Biotechnological Information (NCBI) database (codes 92919067, 1403355, 1403354, 1403353, 1403352, 1403351, 1403350, 29538400, 29538399, 2916726, 1146425, and 1146423 ) were used to design the primers based on the Prifi program (Fredslund et al., 2005).

Amplification of the polyphenol oxidases
gene using specific primers: The amplification of
the fragments flanked by the primers was done using
polymerase chain reaction (PCR). For this purpose,
$150 \mathrm{ng}$ of the sample, $0.4 \mu \mathrm{M}$ of each primer [(P354-F 5'-


GTACCGTCAAATGGTAACTAATGCTCCATGTCCTC-3') and (P2-R 5'-GAGGACATGGAGCATTAGTTACCATTTGACGGTAC-3')], 200 $\mu \mathrm{M}$ of the dNTPs and $0.25 \mathrm{U}$ of $\mathrm{GoTaq}^{\circledR}$ (Promega) were used. The thermal cycling profile was as follows: $94^{\circ} \mathrm{C}$, four minutes; 30 cycles of $94^{\circ} \mathrm{C}$, one minute; $60^{\circ} \mathrm{C}, 30$ seconds; $72^{\circ} \mathrm{C}$, two minutes; and final extension $72^{\circ} \mathrm{C}$, ten minutes. They were stored at $-20^{\circ} \mathrm{C}$ until being sequenced.

Reverse Transcription (RT)-polymerase chain reaction: Synthesis of CDNA was done with the OneStep RT-PCR kit (QIAGEN), following the manufacturer's recommendations. The previously obtained RNA and primers (P354-F 5'GTACCGTCAAATGGTAACTAATGCTCCATGTCCTC-3' and P2R5'-GAGGACATGGAGCATTAGTTACCATTTGACGGTAC-3') were used as the template. The control was the lulo roots in which the retrotranscriptase was not activated.

Southern blot: Single and double digestions of $10 \mu \mathrm{g}$ DNA were carried out with $50 \mathrm{U}$ of the restriction enzymes Eco RI and Hind III. The digestion product was separated at $60 \mathrm{~V}$ for five hours, using electrophoresis in agarose gel at 1\% TAE 1X and stained with ethidium bromide. The gel was submitted to depurination, using a solution of $250 \mathrm{mM} \mathrm{HCl}$, stirring gently for 11 minutes, washing twice with distilled water, and submitting it to denaturation for 25 minutes, using a solution of $1.5 \mathrm{M} \mathrm{NaCl}$ and $0.5 \mathrm{M} \mathrm{NaOH}$. Once again, the same substance was washed with distilled water and neutralized for 30 minutes with a solution of $1.5 \mathrm{M} \mathrm{NaCl}$ and $0.5 \mathrm{M}$ Tris- $\mathrm{HCl}(\mathrm{pH}=7.5)$. The transference was done overnight using SSC 20X ( $3 \mathrm{M} \mathrm{NaCl} ; 300 \mathrm{mM}$ trisodium citrate, $\mathrm{pH}=7.0$ ) as a transfer buffer. The membrane was washed for one minute with $6 \mathrm{X}$ SSC, oven dried at $80^{\circ} \mathrm{C}$ for two hours, and prehybridized at $42^{\circ} \mathrm{C}$ for one hour. Then, $100 \mathrm{ng}$ of the PCR product obtained with the P2R and P354 primers were used as a probe and marked according to the recommendations of the ECL Direct Nucleic Acid Labeling and Detection Systems kit (AMERSHAM).

Bioinformatic methods: In order to determine the consensus of sequenced fragments, these were aligned using the MultAlin program version 5.4.1 (Corpet, 1988), CAP3 (Huang and Madan, 1999) and the CLUSTALW tool (Thompson et al., 1994). The identity analyses with respect to the database and the homology of all sequences obtained from extracting the DNA and cDNA were done using the NCBI BLAST application (Altschul et al., 1997). The translation of the nucleotide sequences of lulo var. Castilla was done using the BioEdit Sequence Alignment Editor program (version 7.0.9.0, 2007), and the tool Translate (which used alternative beginnings) of the ExPASy Proteomics server belonging to the Swiss Institute of Bioinformatics (SIB). To establish the catalytic domains, the InterPro (EMBL-EBI) and BLASTp (NCBI) programs were used. For analysis of the catalytic domains and the functional sites of the protein sequences, the InterPro database (Zdobnov and Apweiler, 2001) was used.

\section{RESULTS}

DNA extraction: The DNA extraction from young lulo leaves was evaluated in agarose gel at $1 \%$ stained with ethidium bromide. The DNA samples had an average concentration of $133 \mathrm{ng} \mu \mathrm{L}^{-1}$ and an $\mathrm{A}_{260} / \mathrm{A}_{280}$ ratio=1.55. Data were recorded permanently with digital photography using a (Nikon-Japan) D-100.

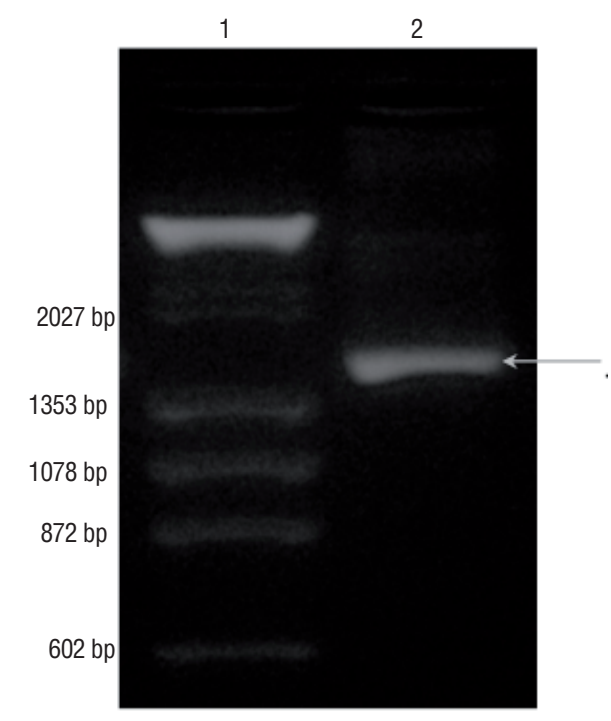

Figure 1. Electrophoresis in agarose gel at 2\%. Lane 1: molecular weight marker (mixture of lambda DNA digested with BstE II and DNA of the bacteriophage $\Phi \times 174$ digested with Hae III). Lane 2: polymerase chain reaction product using DNA from leave $s$ with primers $\mathrm{P}_{3-54-\mathrm{R}}$ and $\mathrm{P}_{2-\mathrm{F}}$

Table 1. Characteristics of the primers used to amplify the lulo polyphenol oxidases.

\begin{tabular}{|c|c|c|c|}
\hline Direction of amplification & Sequence of synthesized primer & Length (pb) / mol wt $\left(\mathrm{g} \cdot \mathrm{mol}^{-1}\right) / \% \mathrm{GC}$ & $\operatorname{Tm}\left({ }^{\circ} \mathrm{C}\right)$ \\
\hline Primer 5'-3‘ (P3-54-F) & 5'-GTACCGTCAAATGGTAACTAATGCTCCATGTCCTC-3‘ & $35 / 10666.0 / 45.7$ & 62.7 \\
\hline Primer 3`-5‘ (P2-R) & 5’-GAGGACATGGAGCATTAGTTACCATTTGACGGTAC-3“ & $35 / 10835.1 / 45.7$ & 62.7 \\
\hline
\end{tabular}


Primer design: Based on the analyses of the sequences corresponding to the genes and mRNAs of the PPO enzyme stored in the databases, two primers were designed. Analyses of the primers were carried out with the Oligo Calculator application (Kibbe, 2007). The hybridization temperature $(\mathrm{Tm})$, primer length, and percent $=\mathrm{GC}$ content were determined (Table 1). There were no dimers or hairpins that could interfere in the process of amplifying DNA chains.

Amplifying and sequencing the fragment corresponding to the lulo polyphenol oxidases: $A$ fragment of about $1,700 \mathrm{pb}$ was amplified and was found in the range of the PPO genes identified in numerous vegetable species, from 1,700 to $2,000 \mathrm{pb}$ (Cary et al., 1992; Goldman et al., 1998; Demeke and Morris, 2002), as seen in Figure 1.

The resulting sequence of this PCR product was 1,728 pb (Figure 2), which was compared with some databases, finding high homology with sequences for PPOs in other Solanaceae (Table 2). These results confirmed the identity of the sequence obtained for the lulo PPO.

Amplification of regions 3'and 5' of the polyphenol oxidase gene in Iulo: In accordance with the evaluation of the nucleotide sequence obtained, the area corresponding to the catalytic domain (tyrosinase) was identified. It was

\begin{abstract}
ATTTATTGGTTGTCTGCCTGATTTGTTTTGCCAACCCAGTTAGCGTGTGCATTCTGGGCTTGGCTTCTGTGTGCACCCATCCCTCGGTG AATTCTACTCCAATTCTTGGTAGTATAGCCCATAAGTATTAATGAAACTTGGAGGGAGCGTGTTCATACCATGTTGCTGTGCGCTTC СCTCACTGCCTCGATGGAGGGTTGGAACAAAATTCCATTATTTACCAAGTTTCCCTCTTCTTGACTGACTAAGCTACGCATTCGTCAGC CTGCTCATGCTGCTGATGAGGAGTGTATCGCCAAGTACAATTTGGCTATTAGCGGAATGAAGGATCTTGATAAGACAGAACCTTCAAAT CCCTATTGGGCTTTCAAGCAACAAGCCAATATACATTGTGCTTATTGGAACGGTGCTTACGCAATTGGATGACAAAGTGTTACAAGTTC ATAACTCATGGCTTTTCTTCCCTGTTCCATAGATGGTACTTGTACTTCTACGAGAGAATCGTTGGGATACAAATCATCGACTGATCCAA CTTTCGCTTTGCCATACTGGAACTGGGACCATCCAAAGGGCATGCGTATGCCTCCTATGTTCGATCGTGAAGGGACTGCCCTATACGAC GAAAGTGAGCGTAATCCCAACAGATAGTCCGTCAACGGGAACCGTTATATGGATCTTGGTTCTATTCGGCGACCAAGTCCAAACAACCT CGAAATACAGTTGATGAGTAATAACTAACTCAAGTACCGTCAAATGGTAACTAATGTACCGTCAATGGTACTATGCTCCATGTCCTCG GATGTTTGCAAGTGGCGCGCCTTATGTTCTCGGGAATAACGTTGGAAGCCCGGGAACCATTGAAAGGCCATCCCTCACAGTGTCCTGT ACACATTTGGGACTGGTACAGAGCCGAGGTTACAACTCTTAGCCCTAATGGTGAAACGGTCATACGGTGAGAGATATGGGTCATTTCTA CTCAGCTGGTTTAGGACCCCGGATTTTCTTTTGCCACCACGGTAATGTGGACCGGATGTGGAGCGAATGGAAACGGGAATCAGGAGGGA AAAGAAGGGATCTCTCACATAAAGATTGGTTGAACTCGGAGTTCTTTTTCTACGAGTGAAGACAAAAACCCTTACCGTGTGAAAGTCGG AGACTGTTTGGACACCAAGAAGATGGGGTATCGATTACGCACCAATGCCAACACCGTGGCGTAACTTCAAGCCAAAAACAAAGGCCTCA GTTGGGGAAACGCTAGATACAAGGTTCACTTCCGTCCAGTCAGCACAGGGTATTCCCACTCGCGAAAGATGGACAAAGCCATTTTCGG TTGTCCCATCCAAACTAGGGCCAGGCTTTCATTCCGAAGAACTCAAACAGGAGGAAACAGTGGGCAACAAAAGAAAAGGGACAGAAGTC GCCTTAAACACGCTGTTCACGCAAGCGCAAACCATTTAGCCATGTCTTTGCACTTTATTTGCACGACAAGAGGCTCAATTTTTTAAGGGG GGTCTCCGAGCGTGGATCTTCACCCCTGTAGTAAATTGCCTGTGTGAGCAACACAATATAATGGTTTGTTGCAATGCGGGGTTGAATG TTAGACCGTGGAACACCAAAGGGGGACCGAAGAATATCGACCGCGGGGGAAAGACGCTATTAATCGCATATATTGGTGGCCCACACACA TGTTTTACACACGAGAGTTTGGCGGACAGAAGAATTTACACCATGAAGATCCGTGGAACAGCCGACACACGGTTTTTACCTGAACCGAG AGGGCGTAGAGTAAGCAATGTAACACTGGGATTCTGGTGGACCCTT
\end{abstract}

Figure 2. Partial nucleotide sequence corresponding to the polyphenol oxidase gene identified in lulo.

Table 2. Levels of similarity between the nucleotide sequence identified in lulo and the polyphenol oxidase genes of other related species.

\begin{tabular}{lccc}
\hline Accession & Description & E-value & \% Identity \\
\hline GQ149350.1 & Solanum melongena PPO mRNA, partial cds & 0.0 & 84 \\
GQ149349.1 & S. melongena PPO gene, complete cds & 0.0 & 84 \\
HM015902.1 & S. melongena chloroplast PPO precursor (PPO2) gene, complete cds & 0.0 & 83 \\
U22922.1 & Solanum tuberosum tuber PPO (POT33 allele) mRNA, complete cds & 0.0 & 82 \\
GQ246219.1 & S. melongena chloroplast PPO precursor (PPO) gene, complete cds & 0.0 & 83 \\
Z12836.1 & Lycopersicon esculentum gene for PPO & 0.0 & 0.0 \\
AK247107.1 & Solanum lycopersicum cDNA, clone LEFL1035DA02, HTC in leaf & $7.00 \mathrm{E}-177$ & 78 \\
Z12833.1 & L. esculentum gene for PPO & $1.00 \mathrm{E}-169$ & 78 \\
Z12835.1 & L. esculentum gene for PPO & $1.00 \mathrm{E}-144$ & 82 \\
AB018244.1 & S. melongena EEF26 mRNA for PPO-like protein, partial cds & $2.00 \mathrm{E}-107$ & 84 \\
AJ697805.1 & L. esculentum partial PPO gene (5' fragment) & $2.00 \mathrm{E}-107$ & 84 \\
AJ635323.1 & L. esculentum partial mRNA PPO A (773 bp more 5' fragment) & $1.00 \mathrm{E}-75$ \\
FJ573257.1 & Solanum quitoense PPO gene, partial cds & $1.00 \mathrm{E}-70$ \\
DQ356947.1 & Nicotiana tabacum PPO gene, partial cds & 78 \\
Y12501.1 & N. tabacum mRNA gene for PPO & 80 \\
U22923.1 & Solanum tuberosum tuber PPO (POT72 allele) mRNA, partial cds & $1.00 \mathrm{E}-70$ \\
AJ635324.1 & L. esculentum partial PPO gene A (731 bp more 3' fragment) & 80 \\
\hline
\end{tabular}


necessary to amplify the nontranslated regions $3^{\prime}$ and $5^{\prime}$ in order to complete the PPO gene sequence. For this purpose, primers were designed for regions 5' and 3', using the PriFi program (Fredslund et al., 2005) and the following sequences of fragments 5 ' and 3 ' for potatoes, tomatoes, and eggplants, which were reported in the NCBI databases (46275223, 46517926, 46517924, 46275225, 46405865, 404586, 404584, and 251851952). The evaluation of each pair of primers was done using the OligoAnalyzer program of the Integrated DNA Technologies - IDT (http:// www.idtdna.com/analyzer/applications/oligoanalyzer). Based on the analyses of the sequences of PPOs genes reported on the NCBI database the following primers were designed to amplify the initial and terminal regions of the PPO gene of lulo. Primers for 5' region were 15PForward 5'-TGCCACTCTCAAATCTTC-'3 and I5P-Reverse 5'-CGGAGCTTAGTGGCAGAAG-'3 and Primers for 3' region were I3P-Forward 5'-ACCAATGCCAACACCATG-'3 and I3P-Reverse 5'-TTCATCAAAGTGTAATCTCAGC-'3. northwestern.edu/biotools/oligocalc.html) (Kibbe, 2007) was used to determine the hybridization temperature (Tm), primer length, and percent GC content (Table 3). The absence of dimers and hairpin formations that could interfere in the processes of amplifying the DNA chains was confirmed.

For the amplification, $150 \mathrm{ng}$ of the sample, $0.4 \mu \mathrm{M}$ of each primer, $10 \mathrm{mM}$ triphosphate deoxynucleoside, and $0.25 \mathrm{U}$ of $\mathrm{GoTaq}^{\circledR}$ (Promega) were used. The thermal cycling profile was as follows: $94^{\circ} \mathrm{C}$, four minutes; 30 cycles of $94^{\circ} \mathrm{C}$, one minute; $60^{\circ} \mathrm{C}, 30$ seconds, $72^{\circ} \mathrm{C}$, two minutes, and finally $72^{\circ} \mathrm{C}$, ten minutes. The analysis of the sequence corresponding to region 5' generated a fragment of $232 \mathrm{pb}$, while the one corresponding to region 3 ' produced a fragment of $472 \mathrm{pb}$. In both cases, the sequences showed high homology with those reported in the databases for eggplant and potatoes, with identities from 60 to $80 \%$. Assembling these sequences with the initial one resulted in a sequence of 1,964 pb (Figure 3).

Table 3. Characteristics of the primers used to amplify regions 3' and 5' of the polyphenol oxidase in lulo.

\begin{tabular}{|c|c|c|c|}
\hline Direction of amplification & Sequence of synthesized primer & Length $(\mathrm{pb}) / \mathrm{mol}$ wt $\left(\mathrm{g} \cdot \mathrm{mol}^{-1}\right) / \% \mathrm{GC}$ & $\operatorname{Tm}\left({ }^{\circ} \mathrm{C}\right)$ \\
\hline Primer 5‘-3‘ (I5P-F) & 5'-TGCCACTCTCAAATCTTC-3‘ & $18 / 5369.5 / 44.4$ & 49.4 \\
\hline Primer 3‘-5‘ (I5P-R) & 5'-CGGAGCTTAGTGGCAGAAG-3، & $19 / 5917.9 / 57.9$ & 55.5 \\
\hline Primer 5'-3، (I3P-F) & 5'-ACCAATGCCAACACCATG-3“ & $18 / 5421.6 / 50.0$ & 53.6 \\
\hline Primer 3‘-5‘ (I3P-R) & 5'-TTCATCAAAGTGTAATCTCAGC-3' & $22 / 6693.4 / 36.4$ & 50.7 \\
\hline
\end{tabular}

\begin{abstract}
TTAGGT TCCACT T CAAAGCCCT CT CAACTA T TCCACCA TGGAAAA CGTAA CAAAAC T T T CAAAGT CT CA TGCAAGG TTAC CAA TAA TAA T GGT GA C CAAAA C CAAAAT TGT GT T GA TAGGAGAAATGTGCTTCTTGGT T TAGGAGGGATGTA

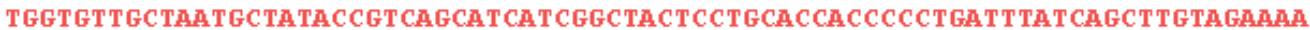
GCCAATTTATTGGTTGTCTGCCTGATTTGTTTTGCCAACCCAGTTAGCGTGTGCATTCTGGGCTTGGCTTCTGTGT GCACCCA TCCT CGGTGAAT T CTACT C CAAT TCT TGGTAGTA TA TAGCCCA TAAGTA T TAA T GAAACT TGGAGGGA GCGTGTTCATACCATGTTGCTGTGCGCTTCCCTCACTGCCTCGATGGAGGGT TGGAACAAAATTCCATTATTTACC AAGTTTCCCTCTTCTTGACTGACTAAGCTACGCATTCGTCAGCCTGCTCATGCTGCTGATGAGGAGTGTATCGCCA AGTA CAA T T T GGCTA T TAGCGGAA T GAAGGA T CT T GA TAAGA CAGAA C C T T CAAA T C C TAT T GGGCT T T CAAGCA ACAAGCCAATA TACA T TGTGCT TAT TGCAACGGTGCT TACGCAATT TGA T GACAAAGTGT TACAAGT CAT TAACTC ATGGCTTTTCTTCCCTGT TCCATACATAGATGGTATCTTTCTACGAGAGAATCGTTGGGATACAAATCATCGACTG AT CCAACT T TCGCT TTGCCATACTGGAACTGGGACCATCCAAAGGGCATGCGTATGCCTCCTATGTTCGATCGTGA AGGGA CTGCCCTATA CGA CGAAAGTGAGCGTAAT TCCAA CAGATAGT CCGT CAA CGGGAACCGTTATATGGATCTT GGT T CTAT TCGGCGAC CAAGT CCAAA CAACCTCGAAA TACAGT T GATGAGTAA TAACTAACTCTAAGTACCGT CAA ATGGTAACTAATGTACCGTCAATGGTACTATGCTCCATGTCCTCGGATGTTTGCAAGTGGCGCGCCTTATGTTCTC GGGAATAACGTTGGAAGCCCCGGGAACCATT TAAAGGCCAT CCCACACAGTGTCCCA TACACATT TGGGACTGGTA CAGAGCCGAGGT TA CAACTCT TAGCCCTAATGGTGAAA CGGT CATACGGTGAGAGATATGGGT CATTTCTACTCAG CTGGTT TAGGACCCCGGATTT TCTT TTGCCACCACGGTAATGTGGACCGGATGTGGAGCGAATGGAAACGGGAATC AGGA GGGAAAAGAAGGGA TCT CT CA CATAAAGA T TGGT T GAACT CGGAGT TCT T T T CTACGACT GAAGA CAAAAA CCCT TACCGTGT GAAAGT CCGAGACTGTT TGGA CACCAAGAAGATGGGGTATCGAT TACGCACCAATGCCAACACC

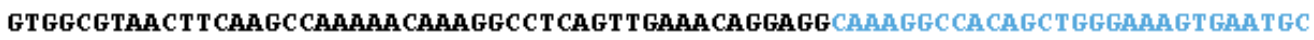

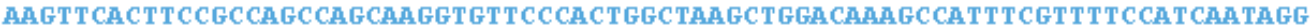

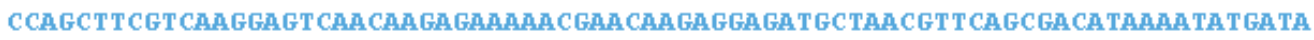
ACAGA GA GTA TA TAAGGT T CGACGT GT T C CT GAAT TT GGA TAAGAAT TTGAATGCT GA T GAGCT TGA CAAGGCAGA GT TCGCGGGGAGCTATACTAGCT TGCCACATGTT CACAGAGCTGGTGATAATAAT CATGTCGCGACTGCTACTTTG CGGCT CGCGGTAACT GAACTGTTGGAGGATATT GCCCTGGAATAT TAAAA CACTAT TGCGGTTACTCTGGTACCAA

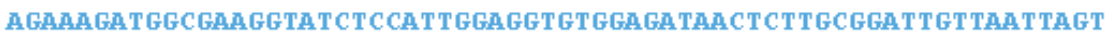

Figure 3. Nucleotide sequence of the lulo polyphenol oxidase, showing region 5' (red), catalytic center (black), and region 3' (blue). 


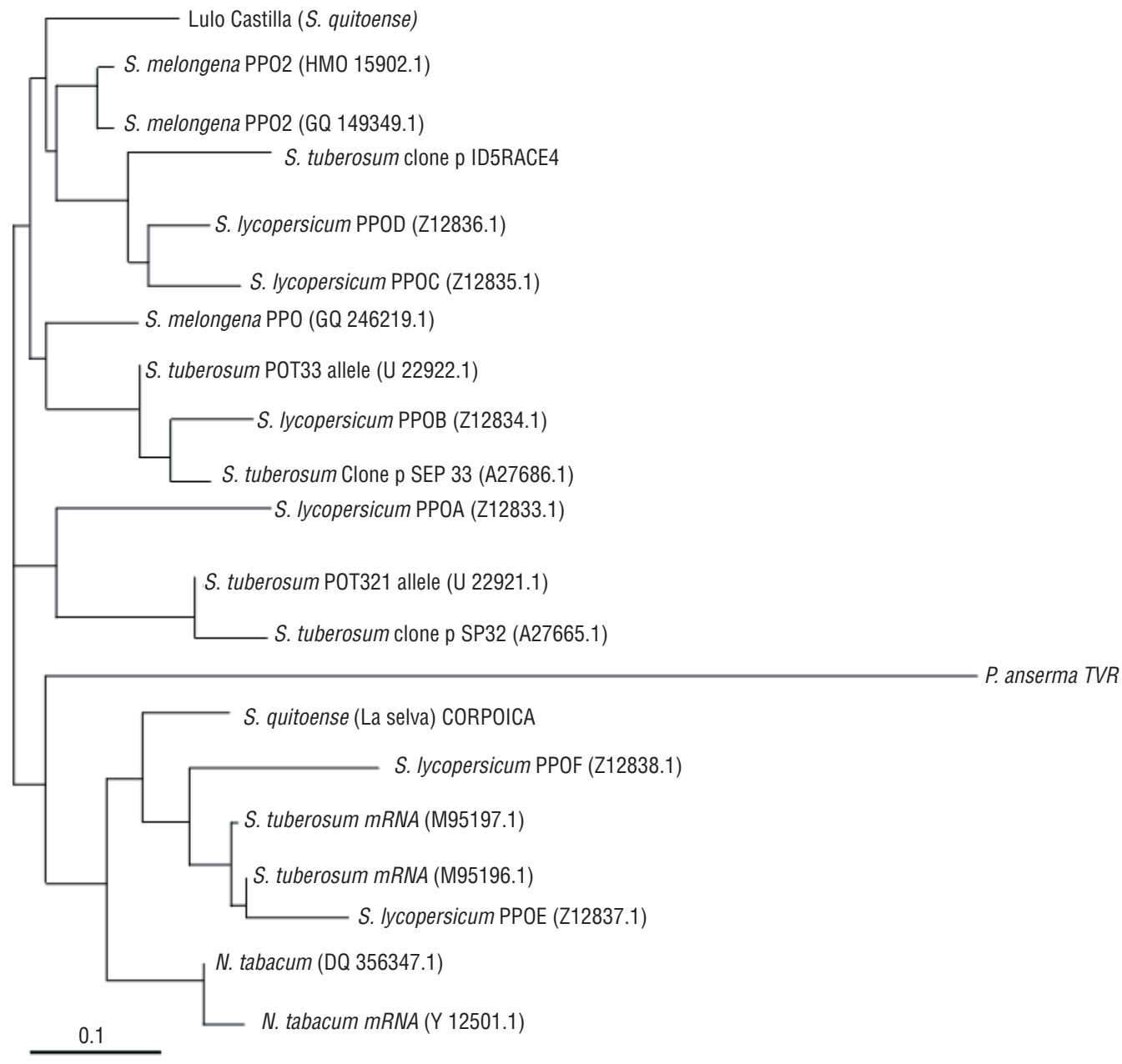

Figure 4. Phylogenetic relationships between the sequences of nucleotides of the Solanaceae polyphenol oxidases, using the TreeView program (Page 1996).

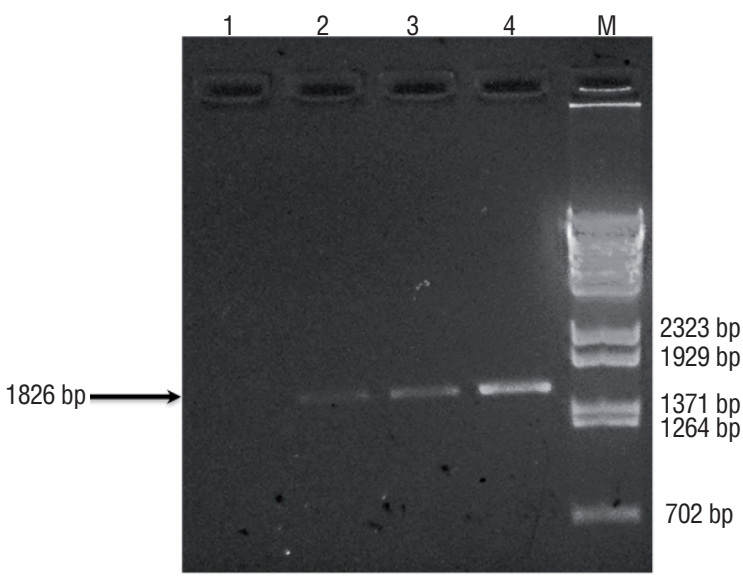

Figure $\mathbf{5}$. Agarose gel at $1 \%$, RT-polymerase chain reaction products from roots, inflorescences, and unripe fruit. $\mathrm{M}$ : molecular weight marker (lambda DNA digested with BstE II); Lane 1: negative control (without RNA template); Lane 2: RNA sample from roots; Lane 3: RNA sample from inflorescences; and Lane 4: RNA sample from unripe fruit; a fragment of 1,826 pb was amplified for use in all samples
The programs MultAlin (Corpet, 1988), CLUSTALW (Thompson et al., 1997), and CAP3 (Huang and Madan, 1999) were used to carry out progressive alignments of multiple sequences.

Phylogenetic analysis of the polyphenol oxidase sequences in Iulo: The phylogenetic evaluation of the sequences that had higher values in the alignment was compared with the ones obtained, determining that they were grouped on the branch corresponding to the group of Solanum melongena (Figure 4). This is an expected result given that both lulos and eggplants belong to the Leptostemonum clade of thegenus Solanum.

Analysis of the cDNA sequence of the lulo polyphenol oxidase: The amplification of cDNA from the different evaluated tissues used a fragment of equal size to that obtained after amplifying the DNA (Figure 5). There were no introns in the amplified PPO gene nor specific 
ttaggttccacttcaagecctctcaactattccaccatggaaacgtaacaaactttc $\begin{array}{lllllllllllllllllllllll}L & G & S & T & S & K & P & S & Q & L & F & H & H & G & K & R & N & K & T & F\end{array}$ aaagtctcatgcaaggttaccaataataatggtgaccaaaaccaaatggtgttgatagg $\begin{array}{llllllllllllllllllll}K & V & S & C & K & V & T & N & N & N & G & D & Q & N & Q & N & G & V & D & R\end{array}$ agaatgtgcttcttggtttaggagggatgtatggtgttgctaatgctataccgtcagca $\begin{array}{llllllllllllllllllllllllll}R & N & V & L & L & G & L & G & G & M & Y & G & V & A & N & A & I & P & S & A\end{array}$ tcatcggctactcctgcaccaccccctgatttatcagcttgtagaaagccaatttattg $\begin{array}{lllllllllllllllllllll}S & S & A & T & P & A & P & P & P & D & L & S & A & C & R & K & A & N & L & L\end{array}$ gttgtctgcctgatttgttttgccaacccagttagcgtgtgcattctgggcttggcttct

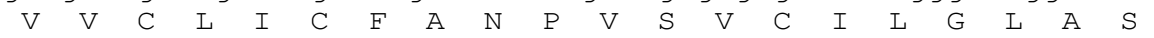
gtgtgcacccatccctcggtgaattctactccaattcttggtagtatatagcccataagt

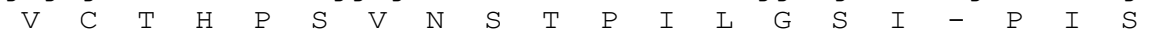
attaatgaaacttggagggagcgtgttcataccatgttgctgtgcgcttccctcactgcC $\begin{array}{lllllllllllllllllllll}I & N & E & T & W & R & E & R & V & H & T & M & L & L & C & A & S & L & T & A\end{array}$ tcgatggagggttggaacaaattccattatttaccaagtttccctcttcttgactgact $\begin{array}{llllllllllllllllllllllllllllllllll}S & M & E & G & W & N & K & I & P & L & F & T & K & F & P & S & S & - & L & T\end{array}$ aagctacgcattcgtcagcctgctcatgctgctgatgaggagtgtatcgccaagtacal $\begin{array}{lllllllllllllllllllllllll}K & L & R & I & R & Q & P & A & H & A & A & D & E & E & C & I & A & K & Y & N\end{array}$ ttggctattagcggaatgaaggatcttgataagacagaaccttcaatccctattgggct $\begin{array}{lllllllllllllllllllll} & A & I & S & G & M & K & D & L & D & K & T & E & P & S & N & P & Y & W & A\end{array}$ ttcaagcaacaagccaatatacattgtgcttattgcaacggtgcttacgcaattggatga $\begin{array}{lllllllllllllllllllll} & F & K & Q & Q & A & N & I & H & C & A & Y & C & N & G & A & Y & A & I & G & -\end{array}$ caaagtgttacaagtcattaactcatggcttttcttccctgttccatacatagatggtat $\begin{array}{llllllllllllllllllllll}Q & S & V & T & S & H & - & \text { L } & \text { M } & \text { A } & \text { F } & \text { L } & \text { P } & \text { C } & \text { S } & \text { I } & \text { H } & \text { R } & \text { W } & \text { Y }\end{array}$ ctttctacgagagaatcgttgggatacaaatcatcgactgatccaactttcgctttgcca $\begin{array}{llllllllllllllllllllllllllllll}L & S & T & R & E & S & L & G & Y & K & S & S & T & D & P & T & F & A & L & P\end{array}$ tactggaactgggaccatccaaagggcatgcgtatgcctcctatgttcgatcgtgaaggg $\begin{array}{lllllllllllllllllllllllll} & Y & W & N & W & D & H & P & K & G & M & R & M & P & P & M & F & D & R & E & G\end{array}$ actgccctatacgacgaaagtgagcgtaatcccaacagatagtccgtcaacgggaaccgt $\begin{array}{lllllllllllllllllllllllllllll}T & A & L & Y & D & E & S & E & R & N & P & N & R & - & S & V & N & G & N & R\end{array}$ tatatggatcttggttctattcggcgaccaagtccaaacaacctcgaaatacagttgatg $\begin{array}{lllllllllllllllllllll}Y & M & D & L & G & S & I & R & R & P & S & P & N & N & L & E & I & Q & L & M\end{array}$ agtaataactaactctaagtaccgtcaaatggtaactaatgtaccgtcaatggtactatg $\mathrm{S} N \mathrm{~N}-\mathrm{L}-\mathrm{V} \mathrm{P} \mathrm{S} \mathrm{N}$ G N $-\mathrm{C}$ T $\mathrm{V}$ N G T M ctccatgtcctcggatgtttgcaagtggcgcgccttatgttctcgggaataacgttggaa

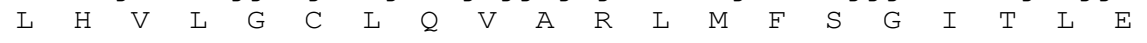
gccccgggaaccattgaaaggccatcccacacagtgtcccatacacatttgggactggta $\begin{array}{lllllllllllllllllllll}A & P & G & T & I & E & R & P & S & H & T & V & S & H & T & H & L & G & L & V\end{array}$ cagagccgaggttacaactcttagccctaatggtgaaacggtcatacggtgagagatatg Q S R G Y N S - P - W - N G H T V R D M ggtcatttctactcagctggtttaggaccccggattttcttttgccaccacggtaatgtg $\begin{array}{llllllllllllllllllll}G & H & F & Y & S & A & G & L & G & P & R & I & F & F & C & H & H & G & N & V\end{array}$ gaccggatgtggagcgaatggaaacgggaatcaggagggaaaagaagggatctctcacat $\begin{array}{llllllllllllllllllll}D & R & M & W & S & E & W & K & R & E & S & G & G & K & R & R & D & L & S & H\end{array}$ aaagattggttgaactcggagttctttttctacgactgaagacaaaacccttaccgtgt $\begin{array}{lllllllllllllllllllll}K & D & W & L & N & S & E & F & F & F & Y & D & - & R & Q & K & P & L & P & C\end{array}$ gaaagtccgagactgtttggacaccaagaagatggggtatcgattacgcaccaatgccaa $\begin{array}{llllllllllllllllllll}E & S & P & R & L & F & G & H & Q & E & D & G & V & S & I & T & H & Q & C & Q\end{array}$ caccgtggcgtaacttcaagccaaaacaaaggcctcagttgaaacaggaggcaaaggcc $\begin{array}{llllllllllllllllllll}H & R & G & V & T & S & S & Q & K & Q & R & P & Q & L & K & Q & E & A & K & A\end{array}$ acagctgggaaagtgaatgcaagttcacttccgccagccagcaaggtgttcccactggct $\begin{array}{llllllllllllllllllll}T & A & G & K & V & N & A & S & S & L & P & P & A & S & K & V & F & P & L & A\end{array}$ aagctggacaaagccatttcgttttccatcaataggccagcttcgtcaaggagtcaacaa $\begin{array}{llllllllllllllllllll}K & L & D & K & A & I & S & F & S & I & N & R & P & A & S & S & R & S & Q & Q\end{array}$ gagaaaacgaacaagaggagatgctaacgttcagcgacataaatatgataacagagag $\begin{array}{llllllllllllllllllll}E & K & N & E & Q & E & E & M & L & T & F & S & D & I & K & Y & D & N & R & E\end{array}$

tatataaggttcgacgtgttcctgaatgtggataagaatgtgaatgctgatgagcttgac

Figure 6. Amino acid sequence of the polyphenol oxidase enzyme in lulo.

transcriptional variants of tissue, the same as for other dicotyledons (Massa et al., 2007; Shetty et al., 2011).

The Bioedit Sequence Alignment (2007) program and the tool Translate (http://expasy.org/tools/dna. $\mathrm{html}$ ) were used to translate the sequences of $1,964 \mathrm{pb}$ of the PPO in lulo. A sequence of 608 amino acids was also obtained (Figure 6).

Southern-blot analysis of hybridization of the genomic DNA of lulo: The results of the southern blot analysis in lulo var. Castilla showed the presence of at 


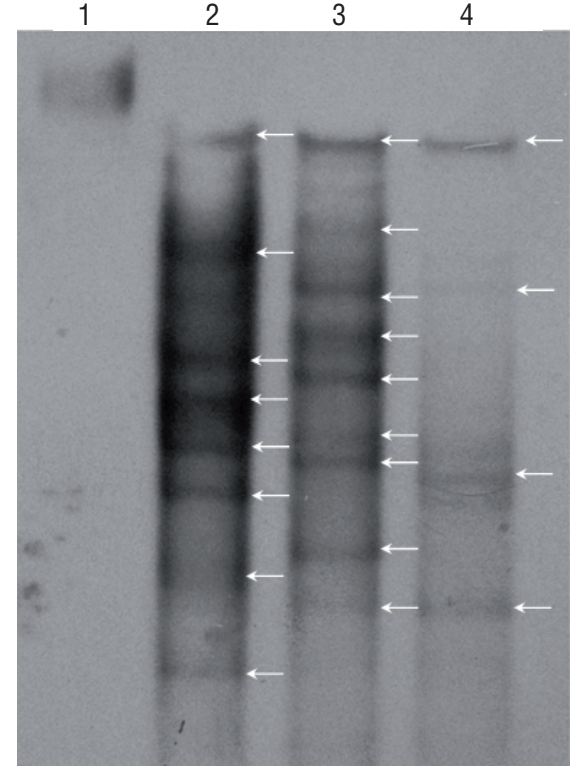

Figure 7. Result of hybridization in which its signal of the probe corresponding to the polymerase chain reaction product is shown. Lane 1: undigested genomic DNA of lulo $(3 \mu \mathrm{g})$; Lane 2: genomic DNA of lulo $(10 \mu \mathrm{g})$ digested with Eco Rl; Lane 3: genomic DNA of lulo $(10 \mu \mathrm{g})$ digested with Hind III; Lane 4: genomic DNA of lulo $(10 \mu \mathrm{g})$ digested with Eco RI-Hind III. least eight hybridization sites (genes), with the probe used for digestion with both enzymes Eco RI and Hind III (Figure 7). These results are in accordance with what was identified by Cary et al. (1992), Thygesen et al. (1995), Beecher and Skinner (2011), Shetty et al. (2011), and Shimizu et al. (2011), who have shown that the PPO genes can belong to one multigene family. Among the Solanaceae, for example, potatoes (Solanum tuberosum) (Thygesen et al., 1995) and tomatoes (Solanum lycopersicum) (Newman et al., 1993) have been found to have six and seven genes, respectively.

\section{DISCUSSION}

The analyses revealed that the protein deduced from the nucleotide sequence in lulo has a domain characteristic of tyrosinases, a family of proteins that includes the PPOs from plants and is closely related to that of hemocyanins found in mollusks and arthropods (Marusek et al., 2006). The database analyses of this sequence showed that the translated amino acid sequences had approximately $50 \%$ identity with the others reported. Although there was a large number (average of $56 \%$ ) of conservative changes in amino acids, this is positive as it reflects a selective pressure to maintain the physicochemical

Table 4. Identity values of the hypothetical protein deduced from the amino acids sequences identified in lulo with respect to the polyphenol oxidases of other plant species.

\begin{tabular}{|c|c|c|c|}
\hline Accession & Description & E-value & $\%$ Identity \\
\hline gb|ACR61398.1| & PPO (Solanum melongena) & $2.00 \mathrm{E}-74$ & 50 \\
\hline gb|ACR61399.1| & PPO (S. melongena) & $2.00 \mathrm{E}-74$ & 50 \\
\hline $\mathrm{gb}|\mathrm{AAA} 85122.1|$ & PPO (Solanum tuberosum) & 8.00E-72 & 48 \\
\hline sp|Q08304.1|PPOB_SOLLC & PPO B, chloroplastic & $3.00 \mathrm{E}-70$ & 54 \\
\hline gb|ADG56700.1| & chloroplast PPO precursor (S. melongena) & 4.00E-70 & 47 \\
\hline sp|Q08306.2|PPOD_SOLLC & PPO D, chloroplastic & 4.00E-69 & 44 \\
\hline $\mathrm{gb}|\mathrm{AAA} 85121.1|$ & PPO (S. tuberosum) & $9.00 \mathrm{E}-67$ & 45 \\
\hline $\mathrm{gb}|\mathrm{ACT} 22523.1|$ & chloroplast PPO precursor (S. melongena) & $3.00 \mathrm{E}-65$ & 52 \\
\hline sp|Q08305.1|PPOC_SOLLC & PPO C, chloroplastic & $6.00 \mathrm{E}-65$ & 43 \\
\hline sp|Q08303.2|PPOA_SOLLC & PPO A, chloroplastic & $6.00 \mathrm{E}-64$ & 44 \\
\hline $\mathrm{gb}|\mathrm{AAB} 22610.1|$ & PPO (Solanum lycopersicum) & 2.00E-59 & 42 \\
\hline sp|Q08296.1|PPOF_SOLLC & PPO F, chloroplastic & $3.00 \mathrm{E}-59$ & 49 \\
\hline sp|Q08307.1|PPOE_SOLLC & PPO E, chloroplastic & $2.00 \mathrm{E}-58$ & 47 \\
\hline $\mathrm{gb} \mid \mathrm{AAA02877.1|}$ & ProPPO (S. tuberosum) & $7.00 \mathrm{E}-57$ & 46 \\
\hline sp|Q06355.1|PPOB_SOLTU & Catechol oxidase B, chloroplastic & $7.00 \mathrm{E}-57$ & 41 \\
\hline gb|AAC69365.1| & PPO (Diospyros kaki) & $2.00 \mathrm{E}-56$ & 42 \\
\hline $\mathrm{gb}|\mathrm{ABE} 96885.1|$ & PPO (Nicotiana tabacum) & $8.00 \mathrm{E}-56$ & 44 \\
\hline emb|CAA73103.1| & PPO (N. tabacum) & $6.00 \mathrm{E}-55$ & 44 \\
\hline $\mathrm{gb}|\mathrm{ACN} 78382.1|$ & PPO (Solanum quitoense) & $9.00 \mathrm{E}-54$ & 45 \\
\hline
\end{tabular}


characteristics of the amino acids in the sequence with the purpose of preserving their enzymatic function (Table 4).

The sequence analyses in the InterProscan database (http://www.ebi.ac.uk/Tools/pfa/iprscan/) identified the central domain of tyrosinase, within which is the copper-binding domain (catalytic center). Moreover, there is a peptide signal that directs the protein towards the chloroplast, specifically to the lumen of the thylakoid (Yurok and Marshall, 2003). Expression of the PPOs has been found to be associated with the response to damage by herbivory or pathogens (Constabel and Barbehenn, 2008). These proteins not only are accumulated in injured leaves, but also in nondamaged ones, distal to the affected site, indicating the presence of a mobile factor that induces the systemic defense response (Matsubayashi 2003; Ryan and Pearce, 2003).

The PPO mechanism of defensive action is not yet clear. Li and Steffens (2002) suggested that the quinones generated by PPO enzymatic action may cause general toxicity for both the pathogen and the plant, producing cell death. The quinones induce alkylation of the plant, decreasing their bioavailability or they can cross-link with other proteins or phenolic compounds in the plant, causing a physical barrier in the cell wall, which blocks the entry of the pathogens into the plant (Li and Steffens, 2002).

According to Halaouli et al. (2006), it can be assumed that the central domain - shared by the tyrosinases, hemocyanins, and catecholases - has similar structural and functional attributes, taking into account: the number of valence and comparable conformational changes during the process of oxygen binding (Mayer, 2006), the spectroscopic and magnetic properties (Maria et al., 2011), and the homology in the primary sequence (Decker and Terwilliger, 2000). The amino acids involved in coordinating the copper ions (i.e. HA1, HA2, HA3 for copper $A$ and HB1, HB2, HB3 for copper $B$ ) follow the general rule: $\mathrm{HA} 1-\mathrm{x}(n)-\mathrm{HA} 2-\mathrm{x}(8)-\mathrm{HA} 3$ and HB1-x(3)-HB2-x(n)-HB3, respectively, where $n$ is a variable of the amount of amino acid residues (García-Borrón and Solano, 2002). Figure 8 shows that at both copper-binding sites A (CuA)

\section{CuA copper-binding site}

Z12838/S60978
Z12837/S61013
Y12501/049912
DQ356947
FJ 573257
U22922
GQ246219
U22921
Z12836/S60980
GQ149350
HM015902
Sq Castilla

CuB copper-binding site

Z12838/S60978
Z12837/S61013
Y12501/049912
DQ356947
FJ573257
U22922
GQ246219
U22921
Z12836/S60980
GQ149350
HM015902
Sq Castilla

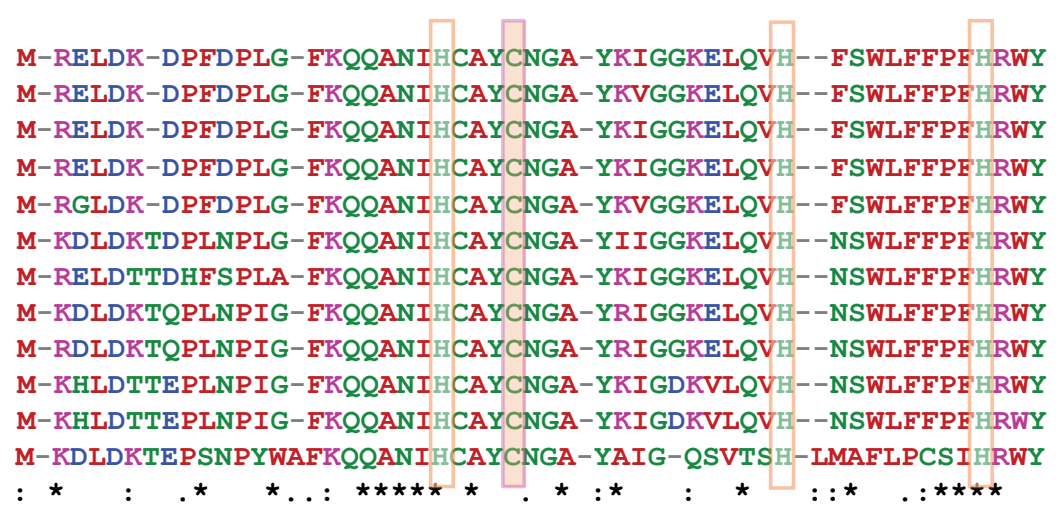

Figure 8. Histidine residues involved in the coordination sphere of coppers A and B atoms of the hypothetical polyphenol oxidase in lulo. 
and $B(\mathrm{CuB})$, the histidine residues follow the rules for distribution established by García-Borrón and Solano (2002). For the CuA binding site, there are 17 amino acids between the first and second residues (His 208His 226) and 9 ones between the second and third (His 208-His 237). For the CuA binding site, there are three amino acids between the first and second residues (His 270-His 374), and there are 46 between the second and third (His 374-His 417). Another characteristic observed in the binuclear catalytic center of copper is cysteine residue ( $\mathrm{C}(\mathrm{HA} 2-2))$, which is involved in the thioester bond with the second histidine of the CuA binding site (Klabunde et al., 1998; Nakamura et al., 2000).

Klabunde et al. (1998) suggested that the thioester bridge optimizes the potential redox (reduction-oxidation) of the binuclear center of copper for oxidation to 0 -diphenol, followed by a quick transfer of electrons. In the Solanaceae PPOs, this cysteine residue is also well conserved; e.g. García-Borrón and Solano (2002) described the active site of the tyrosinases as a hydrophylic sphere enclosed by four alpha-helices that have six imidazole (histidine) residues. This hydrophylic sphere is located within a hydrophobic cage formed by aromatic amino acids and constituted by highly conserved residues $\Phi(\mathrm{HA} 1-7), \mathrm{R}(\mathrm{HA} 3+1), \Phi(\mathrm{HA} 3+3)$, $\Phi(\mathrm{HA} 3+7), \mathrm{E}(\mathrm{HA} 3+8)$ for $\mathrm{CuA} ; \mathrm{D}(\mathrm{HB} 3+4), \Phi(\mathrm{HB} 3+7)$ and $W(\mathrm{HB} 3+10)$ for $\mathrm{CuB}(\Phi=$ aromatic residue). The lulo PPO conserves the following residues: $\mathrm{F}(\mathrm{HA1}-7)$, $\mathrm{R}(\mathrm{HA} 3+1), \mathrm{Y}(\mathrm{HA} 3+3), \mathrm{R}(\mathrm{HA} 3+7), \mathrm{E}(\mathrm{HA} 3+8), \mathrm{D}(\mathrm{HB} 3+4)$, $\mathrm{W}(\mathrm{HB} 3+7)$, and $\mathrm{W}(\mathrm{HB} 3+10)$, as observed in Figure 9.

Analysis of this sequence using NCBI BLASTP (http:// blast.ncbi.nlm.nih.gov/Blast.cgi?PAGE=Proteins) and NCBI Conserved Domain Database (http://www.ncbi.nIm. nih.gov/Structure/cdd/cdd.shtml) applications resulted in the identification of two domains: the tyrosinase functional and the median, the latter has the conserved DWL sequence motif (aspartic acid, tryptophane, and lysine), which is found in both bacteria and eukaryotic organisms primarily in plants. The median domain has an approximate length of 50 amino acids.

An important finding of the sequence analyses was located towards region 3', the UTRA domain (UbiC regulator-associated transcription), a new catalytic one. This has been identified as a conserved domain from the binder to ligand, with a fold similar to pfam04345 in chorismate lyase, which catalyzes the first step in the synthesis of ubiquinone. In bacteria it has been

Z12838/S60978
Z12837/S61013
Y12501/049912
DQ356947
FJ 573257
U22922
GQ246219
U22921
Z12836/S60980
GQ149350
HM015902
Sq Castilla

Z12838/S60978

Z12837/S61013

Y12501/049912

DQ356947

FJ573257

U22922

GQ246219

U22921

Z12836/S60980

GQ149350

HM015902

Sq Castilla

\section{Conversed amino acids in the periphery CuA bindng site}

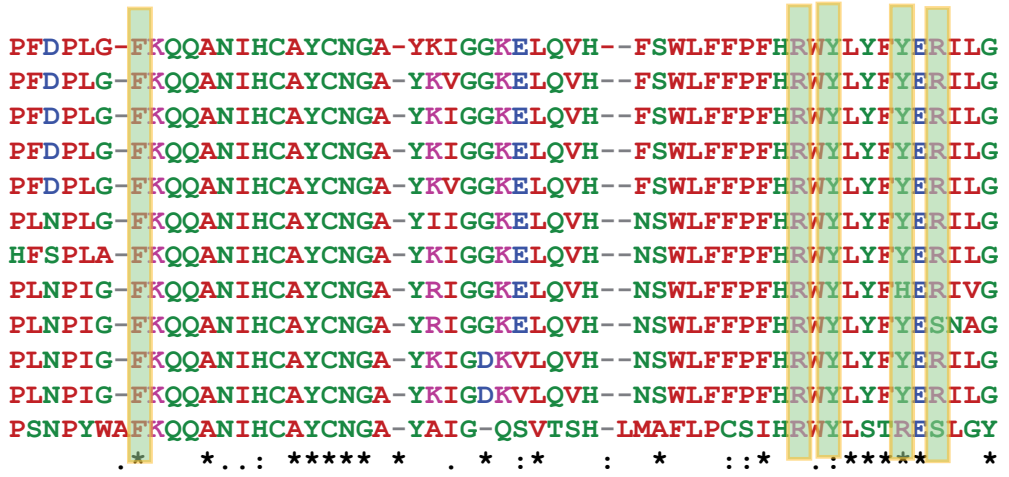

\section{Conversed amino acids in the periphery CuB bindng site}

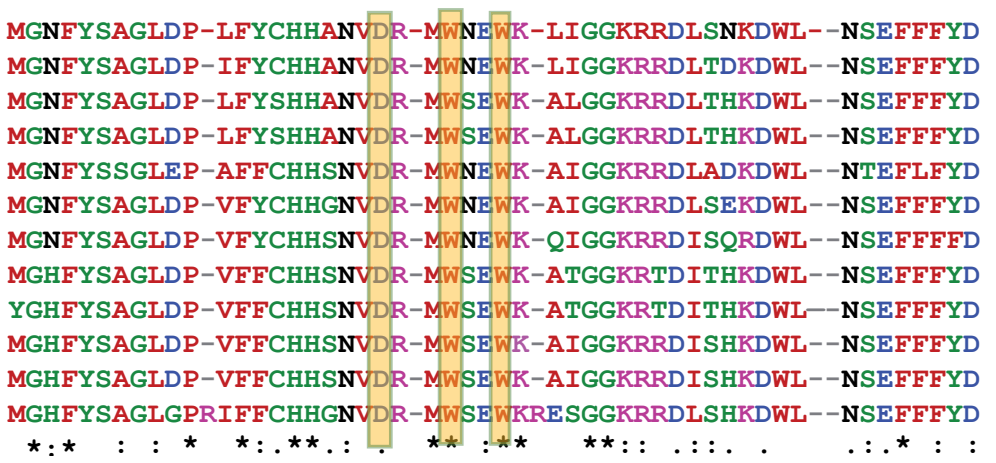

Figure 9. Conserved amino acids in the periphery of the active site of the hypothetical polyphenol oxidase in lulo. 
determined that the UTRA domain modulates the transcriptional activity as a response to the binding of small molecules (Aravind and Anantharaman, 2003). This is the first report about the presence of this domain in plants, where it could be regulating PPO activity as a response to phenolic-type molecules. In addition, the presence of another conserved domain PP01 KFDV (lysine, phenylalanine, glutamic acid, and valine) was established, which is also associated with the chorismate lyase clan - found in many members of the PPOs in plants and plastids (Aravind and Anantharaman, 2003). These areas were recognized at regions between 1,550 to $1,950 \mathrm{nc}$ in the complete sequence of PPO in Iulo.

In accordance with our results, it can be concluded that lulo var. Castilla has at least eight genes for the PPO. The one evaluated lacks introns and has a transcription control region related to the identification of small molecules. The lulo PPO has the characteristic motifs of the PPOs of other Solanaceae. This study constitutes the first report on a complete analysis of the sequencing of the PPO gene in lulo var. Castilla and establishes a starting point for building the knowledge base and developing mechanisms for controlling this important enzyme.

\section{ACKNOWLEDGEMENTS}

\author{
The Universidad Tecnológica de Pereira supported \\ this work.
}

\section{REFERENCES}

Altschul S, Madden T, Schäffer A, Zhang J, Zhang Z, Miller W, Lipman D (1997) Gapped BLAST and PSI-BLAST: a new generation of protein database search programs. Nucleic Acids Res. 25:3389-3402.

Aravind L, Anantharaman VK (2003) HutC/FarR-like bacterial transcription factors of the GntR family contain a small molecule-binding domain of the chorismate lyase fold. FEMS Microbiol. Lett. 222:17-23.

Beecher B, Skinner D (2011) Molecular cloning and expression analysis of multiple polyphenol oxidase genes in developing wheat (Triticum aestivum) kernels. J. Cereal Sci. 53:371-378.

Cary J, Lax A, Flurkey W (1992) Cloning and characterization of a cDNA coding for Vicia faba polyphenoloxidase. Plant Mol. Biol. 20:245-253.

Constabel CP, Barbehenn R (2008). Defensive roles of polyphenol oxidase in plants. In: Schaller A (ed), Induced plant resistance to herbivory. Springer Netherlands Biomedical and Life Sciences, Dordrecht, Part C, pp. 253-270. DOI:10.1007/978-1-4020-8182-8_12.

Corpet $F$ (1988). Multiple sequence alignment with hierarchical clustering. Nucleic Acids Res. 16:10881-10890.

Decker H, Terwilliger N (2000) Cops and robbers: putative evolution of copper oxygen-binding proteins. J. Exp. Biol. 203:1777-1782.
Demeke T, Morris C (2002) Molecular characterization of wheat polyphenol oxidase (PPO). Theor. Appl. Genet. 104:813-818.

Fredslund J, Schauser L, Madsen L, Sandal N, Stougaard J (2005) Prifi: using a multiple alignment of related sequences to find primers for amplification of homologs. Nucleic Acids Res. 33:W516-520.

García-Borrón J, Solano F (2002) Molecular anatomy of tyrosinase and its related proteins: beyond the histidine-bound metal catalytic center. Pigment Cell Res. 15:162-173.

Goldman M, Seurinck J, Marins M, Goldman G, Mariani C (1998) A tobacco flower-specific gene encodes a polyphenol oxidase. Plant Mol. Biol. 36:479-485.

Halaouli S, Asther M, Sigilot J, Hamdi M, Lomascolo A (2006) Fungal tyrosinases: new prospects in molecular characteristics, bioengineering and biotechnological applications. J. Appl. Microbiol. 100:219-232.

Huang, X, Madan A. (1999) CAP3: a DNA sequence assembly program. Genome Res. 9:868-877.

Kibbe W (2007) OligoCalc: an online oligonucleotide properties calculator. Nucleic Acids Res. 35:W43-W46. doi:10.1093/nar/gkm234.

Klabunde T, Eicken C, Sacchettini J, Krebs B (1998) Crystal structure of a plant catechol oxidase containing a dicopper center. Nat. Struct. Mol. Biol. 5:1084-1090.

Li L, Steffens JC (2002) Overexpression in polyphenol oxidase in transgenic tomato plants results in enhanced bacterial disease resistance. Planta 215:239-247.

Maria M, Bostan N, Aslam R, Mustafa B, Safdar W (2011) Type III Multicopper Proteins: A Critical Review. IJBT. 4:575-581.

Martinez MV, Whitaker JR (1995) The biochemistry and control of enzymatic browning. Trends Food Sci. Technol. 6:195-200.

Marusek CM, Trobaugh NM, Flurkey WH, Inlow JK (2006) Comparative analysis of polyphenol oxidase from plant and fungal species. J. Inorg. Biochem. 100:108-123.

Massa AN, Beecher B, Morris CF (2007) Polyphenol oxidase (PPO) in wheat and wild relatives: molecular evidence for a multigene family. Theor. Appl. Genet. 114:1239-1247.

Matsubayashi Y (2003) Ligand-receptor pairs in plant peptide signaling. J. Cell Science. 116:3863-3870.

Mayer AM (2006) Polyphenol oxidases in plants and fungi: going places? A review. Phytochemistry 67:2318-2331.

Medina Cl, Lobo M, Martínez E (2009) Revisión del estado del conocimiento sobre la función productiva del lulo (Solanum quitoense Lam.) en Colombia. Corpoica Cienc. Tecnol. Agropec. 10:167-179.

Nakamura M, Nakajima T, Ohba Y, Yamauchi S, Lee B, Ichishima E (2000) Identification of copper ligands in Aspergillus oryzae tyrosinase by sitedirected mutagenesis. Biochem. J. 350:537-545.

Newman S, Eannetta N, Yu H, Prince J, de Vicente M, Tanksley S, Steffens J (1993) Organisation of the tomato polyphenol oxidase gene family. Plant Mol. Biol. 21:1035-1051.

Page RDM (1996) TreeView: an application to display phylogenetic trees on personal computers. Comput. Appl. Biosci. 12:357-358.

Ryan C, Pearce G (2003) Systemins: a functionally defined family of peptide signals that regulate defensive genes in Solanaceae species. Proc. Natl. Acad. Sci. USA 100:14577-14580.

Schijlen EGWM, Ric de Vos CH, Van Tunen AJ, Bovy AG (2004) Modification of flavonoid biosynthesis in crop plants. Phytochemistry 65:2631-2648. 
Shetty SM, Chandrashekar A, Venkatesh YP (2011) Eggplant polyphenol oxidase multigene family: cloning, phylogeny, expression analyses and immunolocalization in response to wounding. Phytochemistry 72:2275-2287.

Shimizu MM, Melo GA, Brombini dos Santos A, Bottcher A, Cesarino I, Araújo P, Magalhães Silva Moura JC, Mazzafera P (2011) Enzyme characterization, isolation and cDNA cloning of polyphenol oxidases in the hearts of palm of three commercially important species. Plant Physiol. Biochem. 49:970-977.

Strack D, Schliemann W (2001) Bifunctional polyphenol oxidases: novel functions in plant pigment biosynthesis. Angew Chem. Int. Ed. Engl. 40:3791-3794.
Thompson J, Higgins. D, Gibson T (1994) CLUSTAL W: improving the sensitivity of progressive multiple sequence alignment through sequence weighting, position-specific gap penalties and weight matrix choice. Nucleic Acids Res. 22:4673-4680.

Thygesen PW, Dry IA, Robinson SP (1995) Polyphenol oxidase in potato. A multigene family that exhibits differential expression patterns. Plant Physiol. 109:525-531.

Yurok R, Marshall, M (2003) Physicochemical properties and function of polyphenol oxidase: a review. J. Food Biochem. 27:361-422.

Zdobnov E, Apweiler R (2001) InterProScan - an integration platform for the signature-recognition methods in InterPro. Bioinformatics. 17:847-848. 